\title{
Deuterium Tracer Experiments Prove the Thiophenic Hydrogen Involvement During the Initial Step of Thiophene Hydrodesulfurization
}

\author{
Gregory Y. Katsapov • Artur Braun
}

Received: 13 January 2010/ Accepted: 6 June 2010/Published online: 9 July 2010

(C) Springer Science+Business Media, LLC 2010

\begin{abstract}
We reassess literature data and demonstrate that the intermolecular hydrogen transfer occur likely during the primary catalytic interaction between thiophene molecules, rendering it the credible thiophene hydrodesulfurization (HDS) pathway. Deuterium tracer experiments prove that thiophenic hydrogen plays a part in direct $\mathrm{C}-\mathrm{S}$ cleavage, in the initial step of thiophene HDS. Hypothetical surface intermediates for thiophene exchange do not precede, i.e. do not form prior to the surface intermediates for thiophene HDS. Therefore the established thiophene exchange/HDS scheme and the sequence of events are not the viable concepts. Since the deuterium data also indicate that $\mathrm{C}_{4} \mathrm{H}_{5} \mathrm{~S}(\mathrm{a})$-radicals are not formed this means there are no common surface or reaction intermediates for the thiophene exchange and HDS and both reactions proceed parallel.
\end{abstract}

Keywords Thiophene hydrodesulfurization mechanism . Deuterium tracer experiments .

Intermolecular hydrogen transfer $\cdot$ HD exchange

The mechanism of thiophene hydrodesulfurization (HDS) requires further discussion. The authors' interpretation of the previous works that used deuterium as a tracer is mostly inconsistent with their experimental results. At least six

Electronic supplementary material The online version of this article (doi:10.1007/s10562-010-0400-6) contains supplementary material, which is available to authorized users.

G. Y. Katsapov · A. Braun ( $ه)$

Empa. Swiss Federal Laboratories for Materials Science

and Technology, Laboratory for High Performance Ceramics, 8600 Dübendorf, Switzerland

e-mail: artur.braun@alumni.ethz.ch essential facts in these works must be discussed. The first work contains two crucial facts, which escaped the attention of the authors and also went unnoticed by the readers. These and other results invalidate the major proposal of their subsequent works, i.e. that dihydrothiophenes are possible reaction intermediates for thiophene HDS. In reality, exactly past works with the use of deuterium already contain several important deuterium tracer facts, which testified that the thiophenic hydrogen could play a part in direct $\mathrm{C}-\mathrm{S}$ cleavage, in the initial step of thiophene hydrodesulfurization. Our aim is to illustrate that the intermolecular hydrogen transfer may likely occur during the primary catalytic interaction between thiophene molecules and that such mechanism of thiophene transformation can be considered as the credible thiophene HDS pathway.

While thiophene hydrodesulfurization (HDS) has been extensively studied, the main contribution to understanding of potential HDS pathways was made by product distribution and kinetic studies as well as by deuterium tracer experiments. In spite of various reviews on this topic, only some [1-6] are cited here, the key details remain debatable; no agreement was reached even on the initial step of thiophene HDS. There are several proposals for the thiophene HDS pathway. Amberg [2] concluded after product distribution studies that thiophene undergoes hydrogenolysis without prior ring hydrogenation, and that it is followed by a sequence of olefin hydrogenations; i.e. the initial step of thiophene (Th) HDS is the $\mathrm{C}-\mathrm{S}$ cleavage.

$\mathrm{Th}+\mathrm{H}_{2} \rightarrow \mathrm{H}_{2} \mathrm{~S}+1.3$ butadiene, butenes which can

further hydrogenate

Kraus and Zdrazil [7] observed the formation of tetrahydrothiophene (THT) during the thiophene HDS and interpreted this as evidence for a consecutive 
reaction pathway: the ring hydrogenation of thiophene occurs first and is then followed by decomposition of the saturated molecule.

$$
\begin{aligned}
\text { Th }+\mathrm{H}_{2} \rightarrow & \text { Tetrahydrothiophene } \rightarrow \mathrm{H}_{2} \mathrm{~S} \\
& +1.3 \text { butadiene and other hydrocarbons }
\end{aligned}
$$

The Kieran-Kemball [8] idea on the initial partial hydrogenation that facilitates the following $\mathrm{C}-\mathrm{S}$ cleavage seems today as an appropriate compromise which combines the aforementioned two ideas.

$$
\begin{aligned}
\text { Th }+\mathrm{H}_{2} \rightarrow & \text { Dihydrothiophenes } \rightarrow \mathrm{H}_{2} \mathrm{~S} \\
& +1.3 \text { butadiene and other hydrocarbons }
\end{aligned}
$$

Over time, Zdrazil [3] also acknowledged that only a partial saturation of the ring seems necessary in the first step. Sullivan and Ekerdt [9] observed the formation of dihydrothiophenes (DHTs) and THT, and proposed the partial thiophene hydrogenation to 2,5-DHT with subsequent $\mathrm{S}$-elimination as the major path for thiophene HDS.

The above proposals presume the sequence of hydrogenation and $\mathrm{C}-\mathrm{S}$ cleavage or the reverse, whereas Devanneaux and Maurin [10] obtaining the THT in thiophene HDS products proposed another credible two-path route in which thiophene could react either by hydrogenation or by initial C-S cleavage. Vrinat [4] reviewing the HDS kinetic studies also concluded that thiophene hydrogenation and hydrodesulfurization could proceed as two parallel reactions.

The proposed mechanisms meant the external hydrogen involvement (from gas phase) during $\mathrm{S}$ elimination, while Kolboe [11] presented an entirely different idea; he believed that $\mathrm{C}-\mathrm{S}$ cleavage and hydrogen sulfide removal occurs by $\mathrm{S}$ elimination with thiophene $\beta$-hydrogen atoms. I.e. the internal thiophenic $\beta$-hydrogen could involve in the thiophene HDS and the resulting intermediate could be the hypothetical surface diacetylene undergoing rapid hydrogenation. At the same time most of the researchers believed the external hydrogen participates in the initial step of thiophene hydrodesulfurization and the findings sustained by thiophene HDS kinetic studies. One of the first kinetic works carried out by Satterfield and Roberts [12] in 1968 and more recent by Borgna and coworkers [13] in 2003. However, the results of thiophene HDS kinetic studies were also differing; Massoth [14] supported primary butadiene formation whereas Lee and Butt [15] detected THT in small amounts (up to $\sim 3 \%$ ) among thiophene HDS products.

Gellman and coworkers [16] doubted that THT was a likely intermediate in the thiophene HDS. The authors also revealed important kinetic evidence: "Butadiene's rate of appearance is independent of hydrogen pressure..." whereas "its rate of hydrogenation to butene is dependent on hydrogen pressure..." Next evidence was obtained by Gellman et al. [17] in studying the effect of adsorbed sulfur in thiophene HDS. The authors used a ${ }^{35} \mathrm{~S}$ isotope and presumed: "...an Mo-S intermediate is not a step in the HDS mechanism..." Therefore the authors concluded that the desulfurization step occurs via either the Kolboe pathway or a direct hydrogenolysis of $\mathrm{C}-\mathrm{S}$ bonds to form hydrogen sulfide. Hensen and coworkers [18] observed 2,3DHT; 2,5-DHT and THT during another kinetic study on the thiophene HDS and pointed out that (partially) hydrogenated thiophenes and THT are important intermediates in the reaction mechanism. Their proposal favored the Kemball-Kieran pathway [8], whereas Borgna and coworkers [13] presumed that direct sulfur elimination is the main thiophene HDS pathway. Nevertheless, the kinetic data did not permit distinction between possible thiophene HDS mechanisms that are in line with experiments (seven different rate expressions that have been successfully fitted to experimental results were cited in the review [4]), neither to make unambiguous conclusion regarding the role of hydrogen in the initial HDS step. The kinetic data also show that the hydrogenation and hydrodesulfurization occur on separate catalytic sites, supporting the suggestion that both processes proceed in parallel [10]. Therefore the need for using deuterium in thiophene HDS experiments was evident.

Some researchers indirectly used the deuterium thiophene data when they explained the appearance of 2,3DHT, 2,5-DHT and THT. For instance, Lee and Butt [15] discussed the deuterium studies carried out by Smith and coworkers [19] and Cowley [20]. Massoth [14] used the same deuterium results for the kinetic data interpretation. Hensen and coworkers [18] referred to Markel and coworkers' [21] deuterium experiments. As well, Sullivan and Ekerdt [9] pointed out to [8] and [21] deuterium data proposing the 2,5-DHT as an intermediate for the mechanism of thiophene/THT HDS.

More effective was the direct use of deuterium for monitoring the hydrogen sulfide isotopic composition in thiophene HDS products. Mikovsky et al. [22] in deuterium tracer experiments provided a reasonable validation to the Kolboe intramolecular pathway: the $\mathrm{d}_{0}$-hydrogen sulfide was mainly formed during the thiophene deuterodesulfurization. However, Cowley [20] proposed a different idea: the adsorbed thiophenic hydrogen participated in the deuterium exchange might produce the $\mathrm{d}_{0}$-hydrogen sulfide. Later Katsapov and coworkers [23] supported the Kolboe idea: first in deuterium experiments over $\mathrm{Ni}-\mathrm{Mo} / \mathrm{Al}_{2} \mathrm{O}_{3}$ and then in the deuterodesulfurization over other two HDS catalysts [24]. 
McCarty and Schrader [25] favored the Cowley idea on $\mathrm{S}$ elimination in deuterium experiments: hydrogen comes to hydrogen sulfide from "a pool of surface hydrogen species". Markel and coworkers in [21] proposed a different explanation, which was based on the Kemball's [8] view of the initial partial thiophene hydrogenation. The authors [21] stated that DHTs are "possible reaction intermediates for thiophene HDS". Finally, Benson et al. [26] carried out the detailed thiophene deuterodesulfurization study dismissing the Kolboe idea and supported the DHTs' formation as possible reaction intermediates.

Thus, the main ideas on the initial thiophene HDS step $[2,7,8]$ are associated with the external hydrogen whereas the ideas of Kolboe [11] and Cowley-McCarty [20, 25] are related with the internal hydrogen involvement in the initial step of thiophene HDS. Using deuterium can be decisive for the elucidation of the role of hydrogen. In fact, deuterium tracer experiments [20-26] provided already sufficient evidence that the primary $\mathrm{C}-\mathrm{S}$ cleavage occurs with thiophenic hydrogen and this readily accessible information may not be ignored.

The key question regarding the initial thiophene hydrodesulfurization step is thus the following: Does sulfur elimination occur via the intramolecular hydrogen transfer [11] or via the adsorbed thiophenic hydrogen that participated in the deuterium exchange [20, 25], or is there even another potential thiophene hydrodesulfurization pathway?

Therefore, the aim of this letter is to show that several deuterium tracer facts illustrate that thiophenic hydrogen could be involved in the initial thiophene HDS step and the intermolecular hydrogen transfer occurred likely during the primary catalytic interaction between thiophene molecules can be considered as the credible thiophene HDS pathway. At the same time the correct interpretation of results can make a difference; our analysis of latest deuterium tracer data $[21,25,26]$ indicates that factual results of these experiments are totally inconsistent with authors' explanations. At least six important facts of this series must be discussed. The first work [25] contains two crucial facts, which simply escaped the attention of the authors and invalidate the major proposal of [21] that "dihydrothiophenes are possible reaction intermediates for thiophene $H D S$ ". Other data in [21, 26] should be also explained differently, and our explanation dismisses the understanding of thiophene HDS mechanism in $[21,26]$ and its similarity with reactions that occur in transition metal complexes. Since the notion that DHTs are possible reaction intermediates originated from the idea on the initial partial thiophene hydrogenation [8] it is worth to consider the complex scheme proposed in this work in greater detail.

In designing and explaining this scheme, Kieran and Kemball employed the main postulates of exchange studies. The first was about chemisorption interaction of organic molecules during the surface act of exchange reaction [27]-the formation of surface intermediates, followed by ideas on the half hydrogenated state [28]common surface intermediates for the exchange and hydrogenation, and the third on "interconversions" [29]reactions among adsorbed species. These postulates were proficiently employed in [8] and partly used in discussing the thiophene HDS mechanism [21, 26]. However, the authors [21, 26] have not assessed the entire potential of scheme [8]. They used the original Kieran-Kemball idea on the formation of partial hydrogenated thiophenes, but have missed the real opportunity to verify if there exists, in reality, such initial partial hydrogenation of thiophene molecules in their deuterium experiments. We will show here how Kieran-Kemball ideas can be properly assessed in experiments with deuterium. Indeed, in Stage I of the scheme [8] the formation of "associated species $\mathrm{C}_{4} \mathrm{H}_{5} \mathrm{~S}_{(a)}$ " was proposed according to the first exchange postulate (associative thiophene adsorption). The initially formed $\mathrm{C}_{4} \mathrm{H}_{5} \mathrm{~S}_{(\mathrm{a})}$-radicals are hypothetical common surface intermediates (the second postulate) for the thiophene exchange and for hydrogenation to tetrahydrothiophene:

$$
\begin{aligned}
\mathrm{C}_{4} \mathrm{H}_{4} \mathrm{~S}_{(\mathrm{g})} & \leftrightarrow \mathrm{C}_{4} \mathrm{H}_{4} \mathrm{~S}_{(\mathrm{a})} \leftrightarrow \mathrm{C}_{4} \mathrm{H}_{5} \mathrm{~S}_{(\mathrm{a})} \leftrightarrow \mathrm{C}_{4} \mathrm{H}_{6} \mathrm{~S}_{(\mathrm{a})} \\
& \leftrightarrow \mathrm{C}_{4} \mathrm{H}_{7} \mathrm{~S}_{(\mathrm{a})} \leftrightarrow \mathrm{C}_{4} \mathrm{H}_{8} \mathrm{~S}_{(\mathrm{a})} \leftrightarrow \mathrm{C}_{4} \mathrm{H}_{8} \mathrm{~S}_{(\mathrm{g})}
\end{aligned}
$$

Due to the above "interconversions" (the third postulate), $\mathrm{C}_{4} \mathrm{H}_{5} \mathrm{~S}_{(\mathrm{a})}$-radicals could convert into another hypothetical surface intermediates for thiophene HDS $\left(\mathrm{C}_{4} \mathrm{H}_{6} \mathrm{~S}_{(\mathrm{a})}\right.$-radicals), which means the formation of adsorbed dihydrothiophenes (partial hydrogenated thiophenes). Exactly these reaction intermediates in view of $[21,26]$ are responsible for the partial hydrogenation and consequent desulfurization. In the next Stage II and III of the scheme [8] these radicals could desulfurize into a variety of entities including hydrogen sulfide.

In the presence of deuterium, Stage I means appearing of $\mathrm{d}_{1^{-}} ; \mathrm{d}_{2}$-dihydrothiophenes as common reaction intermediates for thiophene hydrogenation and HDS. That is, precisely the external hydrogen (deuterium atoms) could first incorporate into thiophene forming $\mathrm{C}_{4} \mathrm{DH}_{4} \mathrm{~S}_{(\mathrm{a})}{ }^{-}$and $\mathrm{C}_{4} \mathrm{D}_{2} \mathrm{H}_{4} \mathrm{~S}_{(\mathrm{a})}$-radicals. Then, during Stage II and III, this deuterium could relocate into resulting products, and hence must appear in hydrogen sulfide (as DHS and $\mathrm{D}_{2} \mathrm{~S}$-molecules) as well as in $\mathrm{d}_{\mathrm{n}}-\mathrm{C}_{4}$-hydrocarbons. While these details can be certainly verified in D-experiments, these facts escaped the attention of the authors in [25, 26]. Overall, this relationship (thiophene exchange precedes HDS) was generalized in [29]—as "the sequence of events". Kemball presupposed that surface intermediates for the exchange "become converted into" surface intermediates for more profound reactions involving the hydrogen. In [8] this meant that surface intermediates for 
the thiophene exchange could convert into thiophene surface intermediates for HDS. Exactly this way of thinking was used in explaining deuterodesulfurization results [26]: "substantial deuterium incorporation into thiophene before the HDS reaction would further complicate interpretation of the deuterium composition of 1,3-butadiene product" and that meant the authors [26] agreed with the relationship [29], i.e. that exchange reactions precede more profound reactions involving the hydrogen. The results that will be discussed below cast doubts that this scenario is correct.

First, the hypothesis on "the sequence of events" [29] and thereby the relationship of thiophene exchange to HDS was already disputed in [24]. The latter authors proposed that there must be a correlation between the deuterium content in the non-desulfurized (but exchanged) thiophene and in the deuterodesulfurization product (hydrogen sulfide) if in accordance with [29] the surface intermediates for thiophene exchange (hypothetical adsorption forms) are forming prior to the formation of surface intermediates for thiophene decomposition. However, the experiments in [24] did not show a correlation of the deuterium content in unconverted thiophene and in hydrogen sulfide. The authors then reasonably concluded that the adsorption forms for exchange and decomposition "can exist simultaneously not affecting one another". This meant that the concept of "the sequence of events" [29] was not mandatory to explain the experimental observation. Actually, the thiophene HDS is a process parallel to the exchange and the data in [24] had already cast doubt on the related causality of the events [29].

Second, the result and conclusion of [24] were confirmed by the aforementioned two facts in [25]. We can show this by comparison of data $[24,25]$ in Table 1 . The $\mathrm{D}_{\mathrm{Th}^{-}}$and $\mathrm{D}_{\mathrm{HS}^{-}}$-values (designated as in [22]) - the atom fractions of deuterium in the non-desulfurized thiophene and in hydrogen sulfide are directly taken from [24]. The mean deuterium numbers (DN-values) for unconverted thiophene and hydrogen sulfide are taken from the work [25]. Thiophene deuterium distributions for $1000{ }^{\circ} \mathrm{C} \mathrm{MoS}_{2}$ and $\mathrm{PbMo}_{6.2} \mathrm{~S}_{2}$ after 2-h reaction are calculated from Fig. 2 in [25], whereas hydrogen sulfide deuterium distributions are calculated from $\mathrm{DN}_{\mathrm{HS}^{-}}$values. The chosen figures from works $[24,25]$ are included in Table 1. Catalyst $\mathrm{MoS}_{2}$ in Table 1 represents $1000{ }^{\circ} \mathrm{C} \mathrm{MoS}_{2}$ catalyst in [25]. Let us compare the deuterium content obtained in thiophene exchange and HDS, in [24, 25]. Large $\mathrm{D}_{\mathrm{Th}}$-values but small $\mathrm{D}_{\mathrm{HS}}$-values were observed over K-25 and GO-116 catalysts [24]. The high deuterium content in the non-desulfurized thiophene $\left(\mathrm{D}_{\mathrm{Th}}=0.86 ; 0.80\right)$ obtained during the deuterodesulfurization over both catalysts has no effect on the deuterium content in hydrogen sulfide $\left(\mathrm{D}_{\mathrm{HS}}=0.04 ; 0.08\right)$. Small $\mathrm{D}_{\mathrm{HS}^{-}}$values meant the formation mostly of $\mathrm{d}_{0^{-}}$ hydrogen sulfide in deuterium. Lack of correlation between $\mathrm{D}_{\mathrm{Th}^{-}}$and $\mathrm{D}_{\mathrm{HS}^{-}}$-values as well as small $\mathrm{D}_{\mathrm{HS}^{-}}$values meant that supposed $\mathrm{C}_{4} \mathrm{DH}_{4} \mathrm{~S}_{(\mathrm{a})}$-radicals do not convert into hypothetical intermediates for HDS (adsorbed $\mathrm{d}_{2}$-dihydrothiophenes did not form).

Third, the different $\mathrm{DN}_{\mathrm{Th}}$-values $(0.17 ; 1.86)$ were observed in [25] over $\mathrm{PbMo}_{6.2} \mathrm{~S}_{2}$ and $\mathrm{MoS}_{2}$ whereas $\mathrm{DN}_{\mathrm{HS}^{-}}$ values are small and very similar $(0.09 ; 0.05)$. The distinctive $\mathrm{DN}_{\mathrm{Th}}$-values have no effect on corresponding $\mathrm{DN}_{\mathrm{HS}}$-values, i.e. there is lack of correlation in the deuterium content of the initial and final HDS products in [25] as it was in [24] - see Table 1. However, this was not discussed in [25]. At the same time, if the main postulates of the H-D exchange conception employed in [8] are valid, then the deuterium incorporated in Stage I must correlate with deuterium in resulting thiophene exchange and deuterodesulfurization products. This is the 1 st unnoticed fact in [25].

Finally, the data in [25] show that the clear $\mathrm{DN}_{\mathrm{Th}^{-}}$-difference $\left(\mathrm{DN}_{\mathrm{Th}}=0.17\right.$ is more than 10 times less than $\mathrm{DN}_{\mathrm{Th}}=$ 1.86) has little effect on corresponding $\mathrm{DN}_{\mathrm{HYDROCARBON}^{-}}$ values. To illustrate this, we include the data from [25] in our Table 2 where the deuterium incorporation into thiophene shows only minor discrepancy of DN HYDROCARBON$^{-v a l u e s . ~}$ These critical results were obtained in [25] but were not properly explained by the authors [25] (the 2nd fact).

Comparison of data $[24,25]$ provides unambiguous evidence that surface intermediates for exchange are not "converted into" surface intermediates for more profound reactions involving the hydrogen and the relationship of thiophene exchange reaction to HDS process does not mean the chain of events as believed in [8, 26] and [29]. From comparison of data $[24,25]$ it is evident that the external hydrogen could not be involved in the hydrogen sulfide formation. Similar and independent results in $[24,25]$ concerning the hydrogen sulfide formation dismiss

Table 1 Lack of correlation in $\mathrm{D}_{\mathrm{Th}^{-}} ; \mathrm{DN}_{\mathrm{Th}}$ and $\mathrm{D}_{\mathrm{HS}^{-}} ; \mathrm{DN}_{\mathrm{HS}}$-values (selected data from [24, 25])

\begin{tabular}{|c|c|c|c|c|c|c|c|c|c|c|c|c|c|c|}
\hline Ref. & Catalyst & $\mathrm{T}\left({ }^{\circ} \mathrm{C}\right)$ & $d_{o}-T h$ & $\mathrm{~d}_{1}$ & $\mathrm{~d}_{2}$ & $d_{3}$ & $\mathrm{~d}_{4}$ & $\mathrm{D}_{\mathrm{Th}}$ & $\mathrm{DN}_{\mathrm{Th}}$ & $\mathrm{d}_{\mathrm{o}}-\mathrm{H}_{2} \mathrm{~S}$ & $\mathrm{~d}_{1}$ & $d_{2}$ & $\mathrm{D}_{\mathrm{HS}}$ & $\mathrm{DN}_{\mathrm{HS}}$ \\
\hline [24] & $\mathrm{K}-25$ & 310 & 1.1 & 1.9 & 8.4 & 28.4 & 60.2 & 0.86 & - & 92.8 & 5.1 & 2.1 & 0.04 & - \\
\hline [24] & GO-116 & 320 & 1.2 & 3.3 & 13.3 & 35.4 & 46.7 & 0.80 & - & 85.7 & 11.7 & 2.6 & 0.08 & - \\
\hline [25] & $\mathrm{PbMo}_{6.2} \mathrm{~S}_{2}$ & 400 & 84.5 & 14.4 & 1.1 & 0 & 0 & - & 0.17 & 93 & 5 & 2 & - & 0.09 \\
\hline [25] & $\mathrm{MoS}_{2}$ & 400 & 1.2 & 25.9 & 61.8 & 10.5 & 0.6 & - & 1.86 & 95.7 & 3.3 & 1 & - & 0.05 \\
\hline
\end{tabular}


Table 2 Lack of correlation in $\mathrm{DN}_{\mathrm{Th}^{-}}$and $\mathrm{DN}_{\text {HYDROCARBONS }}{ }^{-}$ values (data from Table 1 in [25])

\begin{tabular}{lllllll}
\hline Catalysts & \% Conversion & $\mathrm{DN}_{\mathrm{Th}}$ & $\mathrm{DN}_{\mathrm{BDE}}$ & $\mathrm{DN}_{1-\mathrm{But}}$ & $\mathrm{DN}_{\text {cis-2-But }}$ & $\mathrm{DN}_{\text {trans-2-But }}$ \\
\hline $\mathrm{MoS}_{2}$ & 3.88 & 1.86 & 4.01 & 5.82 & 5.71 & 5.59 \\
$\mathrm{PbMo}_{6.2} \mathrm{~S}_{8}$ & 4.10 & 0.17 & 3.59 & 5.36 & 5.54 & 5.53 \\
\hline
\end{tabular}

Table 3 Conversions of 2,3-DHT over $5 \% \mathrm{Mo} / \gamma-\mathrm{Al}_{2} \mathrm{O}_{3}$ (data from Table 1 in [21]); Th means thiophene

\begin{tabular}{lrr}
\hline $\mathrm{T}\left({ }^{\circ} \mathrm{C}\right)$ & \multicolumn{1}{c}{$\mathrm{Th}$} & $\mathrm{THT}$ \\
\hline 300 & 6.5 & 57.8 \\
330 & 12.6 & 38.4 \\
365 & 17.7 & 15.3 \\
400 & 19.6 & 3.4 \\
\hline
\end{tabular}

the idea on the formation even of partial hydrogenated thiophene; under these thiophene HDS conditions the complete hydrogenation could not also occur prior to the $\mathrm{C}-\mathrm{S}$ bond cleavage. Moreover, our analysis of [25] shows that the explanation of the thiophene HDS pathway-the idea that $\mathrm{d}_{0}$-hydrogen sulfide was formed via deuterium exchange (hydrogen comes to hydrogen sulfide from "a pool of surface hydrogen species")-remains untenable. (a) The deuterium/thiophenic hydrogen atom ratio equals 25/1 in [25]. This casts doubt on the role of "a pool of surface hydrogen" in thiophene HDS. (b) Even if the explanation in [25] is reasonable, then again the $\mathrm{DN}_{\mathrm{Th}^{-}}$ difference $(0.17 ; 1.86)$ must correlate with corresponding $\mathrm{DN}_{\mathrm{HS}^{-}}$and $\mathrm{DN}_{\mathrm{HYDROCARBON}}{ }^{-v a l u e s,}$ but the latter values are all similar, see Tables 1 and 2. Thus two principal facts in [25] - the $\mathrm{DN}_{\mathrm{Th}}$-difference does not correlate with the $\mathrm{DN}_{\mathrm{HS}^{-}}$and $\mathrm{DN}_{\mathrm{HYDROCARBON}}-$ values-leave no doubt that the thiophenic hydrogen directly participates in elimination of sulfur.

Considering data [21] where the authors attempted to prove that dihydrothiophenes are reaction intermediates would be helpful in this connection. Indeed, conversion of 2,3- and 2,5-dihydrothiophenes produced THT and thiophene over $\mathrm{Mo}$ and $\mathrm{Re} / \gamma-\mathrm{Al}_{2} \mathrm{O}_{3}$ catalysts (Table 1,3 in [21]). For that reason the following facts in [21] are essential: One is that the amount of thiophene formed from 2,3 DHT increases in hydrogen HDS experiments with increasing temperature while the amount of THT molecules decreases (Table 1 in [21]). The same trend is observed for 2,5 DHT (Table 3 in [21]). For illustration purposes we include some data from Table 1 in [21] in our Table 3. The data indicate that thiophene and THT could appear as a result of simultaneous dehydrogenation and hydrogenation reactions of 2,3 dihydrothiophenes. That is, the catalytic interaction of two dihydrothiophenes gives thiophene and THT molecules and this should be without doubt identified as the mechanism of intermolecular hydrogen transfer. Furthermore (Table 3), the amount of thiophene increasing and amount of THT simultaneously decreasing due to the conversion of 2,3 DHT, on raising temperature, are consistent with the well-known fact: the process of dehydrogenation intensifies with increasing temperature while the one of hydrogenation declines.

Above information was not explained by the authors [21] and this is the $3 \mathrm{~d}$ critical fact. The 4th fact-a misinterpretation relates to deuterium HDS experiments in [21]. Large amounts of emitted $\mathrm{d}_{0}$-thiophene (87.3\%), $\mathrm{d}_{0}$-THT $(52.4 \%)$ and $\mathrm{d}_{0}-\mathrm{H}_{2} \mathrm{~S}(79.2 \%)$ due to the deuterodesulfurization of 2,3- and 2,5 DHT (see Tables 5, 6 in [21]) are next persuasive evidence which support our identification of these data as the intermolecular hydrogen transfer, but not the kinetic isotopic effects as assumed in [21].

We now address the 5th fact-a major misinterpretation in [26], which gave an incorrect basis for association of thiophene organometallic and reactor studies, when the authors explained the HDS mechanism due to the formation of partial hydrogenated thiophenes as reaction intermediates. The authors examined the deuterium content of 1,3-butadiene (BDE) formed due to the deuterodesulfurization assuming that the exchange occurs as "stage (i)" and the deuterodesulfurization as "stage (ii)". That is, the authors believed the exchange precedes HDS process and therefore the deuterium incorporated in stage (i) would appear in the resulting BDE product. Accordingly the authors subtracted from the average $\mathrm{DN}_{\mathrm{BDE}^{-v}}$ alue (3.47) the average $\mathrm{DN}_{\mathrm{Th}^{-}}$value equals 0.27 obtaining the $\mathrm{DN}_{\mathrm{BDE}^{-}}$ value (3.2), which then used for assessing of possible thiophene HDS pathways.

Let us focus on data from [26], some of which are

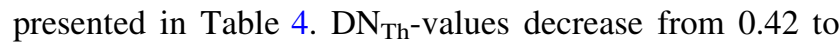
0.05 due to a reduction of thiophene conversion from 10.2 to $0.86 \%$ while $\mathrm{DN}_{\mathrm{BDE}}$-values are similar (see lines $1-3$ in Table 4). This means that decreasing of $\mathrm{DN}_{\mathrm{Th}}$-values in fact has little influence on corresponding $\mathrm{DN}_{\mathrm{BDE}}$-values. At the same time, even if the proposal (the exchange occurs before $\mathrm{HDS}$ ) is correct, all $\mathrm{DN}_{\mathrm{BDE}}$-values must correlate with $\mathrm{DN}_{\mathrm{Th}}$-values; the decrease of $\mathrm{DN}_{\mathrm{Th}}$-values must affect $\mathrm{DN}_{\mathrm{BDE}}$-values. This is evident and logical. The lack of distinct correlation between $\mathrm{DN}_{\mathrm{Th}}$ - and $\mathrm{DN}_{\mathrm{BDE}}$-values [26] is in accordance with data [24, 25]. This means the assumption that dihydrothiophenes are reaction intermediates [21] and the $\mathrm{DN}_{\mathrm{BDE}}$-subtraction procedure [26] are mistaken. The factual experimental results $[25,26]$ make the author's speculations [26] related to deuterium incorporation into different positions of 1,3-BDE and the 
Table 4 Data over $\mathrm{PbMo}_{6.2} \mathrm{~S}_{8}$ at $400{ }^{\circ} \mathrm{C}$, experiment A (selected from Tables 2, 3 in [26])

\begin{tabular}{llllll}
\hline Reaction number & 1 & 2 & 3 & 4 & 5 \\
\hline 1 Conversion C $_{4}$ 's (\%) & 10.2 & 8.09 & 6.81 & 2.63 & 0.86 \\
$2 \mathrm{DN}_{\mathrm{Th}}$ & 0.42 & 0.29 & 0.23 & 0.08 & 0.05 \\
$3 \mathrm{DN}_{\mathrm{BDE}}$ & 3.43 & 3.44 & 3.45 & 3.74 & 3.30 \\
41 -Butene (\%) & 47.7 & 52.0 & 53.3 & 67.7 & 70.8 \\
51,3 -BDE (\%) & 3.50 & 4.67 & 5.65 & 10.1 & 29.2 \\
$6 \mathrm{~d}_{0}-1,3-\mathrm{BDE}(\%)$ & 0.77 & 1.00 & 1.10 & 1.77 & 2.55 \\
\hline
\end{tabular}

subsequent choice of possible thiophene HDS pathways also simply unproductive.

We now point to the 6 th fact-a controversial issue about the primary HDS products in [26]. It was stated that 1,3-BDE is the first desulfurized product. However, it appears that not only 1,3-BDE but also 1-Butene (1-But) emerges as the primary product; see lines 4,5 in Table 4 . The initial large amount of 1-Butene (47.7 at $10.2 \%$ conversion) increases with decreasing of thiophene conversions (70.8 at $0.86 \%$ conversion) i.e. the latter 1 -But amount is twice that of 1,3-BDE (29.2). Why 1-Butene should not be considered as the primary HDS product?

The last essential detail in [26] escaped attention too: the amount (\%) of $\mathrm{d}_{0}-1,3-\mathrm{BDE}$ molecules is rising, slowly but systematically, due to reducing of thiophene conversions from 10.2 to $0.86 \%$ (see line 6 in Table 4). This phenomenon seems to be a measurable indication for involving of thiophenic hydrogen in the formation of $\mathrm{d}_{0}-1,3$-BDE molecules in the presence of deuterium. It appears that especially low conversion experiments (and changing other reaction conditions of the thiophene deuterodesulfurization) may be helpful.

In conclusion Deuterium tracer experiments [20-26] unequivocally prove the thiophenic hydrogen plays an evident part in direct $\mathrm{C}-\mathrm{S}$ cleavage, in the initial step of thiophene hydrodesulfurization. Previous results $[21,25$, 26] do not support the initial thiophene partial hydrogenation pathway by testifying that DHTs are not reaction intermediates as believed in [21, 26]. Hypothetical surface intermediates for thiophene exchange do not precede, i.e. do not form before, the surface intermediates for thiophene HDS. Therefore the thiophene exchange/HDS scheme [8] and the sequence of events [29] (the thiophene exchange occurs before HDS [26]) are not the viable concepts. Since the deuterium data also indicate that $\mathrm{C}_{4} \mathrm{H}_{5} \mathrm{~S}_{(\mathrm{a})}$-radicals are not formed this means there are no common surface or reaction intermediates for the thiophene exchange and HDS and both reactions proceed parallel. Independent results [24] and [25] cast serious doubt upon the main H-D exchange postulates (key ideas of deuterium exchange reactions) used in designing the exchange/HDS scheme [8] and putting these ideas into practice [26]. The most important facts in [24-26] - there is no correlation of the deuterium content in the initial and final thiophene deuterodesulfurization products-must be taken into account. Exactly low conversion experiments [25] alone reject the Cowley-McCarty idea [20, 25] that thiophenic hydrogen participated in deuterium-thiophene exchange could then produce the $\mathrm{d}_{0}$-hydrogen sulfide.

Overall, the assessment of the possible thiophene HDS pathway can be done as following. If we will take the average value of 3.47 of $\mathrm{DN}_{\mathrm{BDE}}$ as a reasonable measurement in HDS experiments [26] (already knowing that thiophene exchange is parallel to HDS) then this $\mathrm{DN}_{\mathrm{BDE}^{-}}$ value would be closer to the Kolboe pathway [11]. At the same time according to [11] only two hydrogen atoms may remain in the hypothetical $\mathrm{C}_{4}$-intermediate (diacetylene), and hence mostly $d_{4}$-BDE must form in the presence of deuterium via this intramolecular pathway. However, as we can see (Table 3, reaction number 5 in [26]) the $\mathrm{d}_{3}$-BDE molecules had the highest content of deuterium $=0.301$, while the $\mathrm{d}_{4}$-BDE-value was 0.275 followed by $\mathrm{d}_{2^{-}}, \mathrm{d}_{5^{-}}$and $\mathrm{d}_{6}$-BDE-values of $0.176,0.145$ and 0.0290 respectively. These figures make the potential Kolboe pathway to a certain extent less persuasive.

On the other hand, low $\mathrm{d}_{0^{-}}$and $\mathrm{d}_{1}$-BDE values $=0.0255$ and 0.0491 , respectively, were also obtained in experiments (see Table 3, reaction number 5 in [26]). What do these figures tell us? The explanation [26], "there must be an exchange step in the HDS process that allows their formation" seems very unlikely. Our analysis has already shown that the exchange reaction has little influence on the thiophene HDS process. Nevertheless, the formation of $\mathrm{d}_{0^{-}}$and $\mathrm{d}_{1}-\mathrm{BDE}$ molecules is to some extent quite indicative. It means that there exists an excess of hydrogen atoms in thiophene deuterium experiments [26], which is not in line with the Kolboe intramolecular pathway [11].

In view of that, the appearance and measured linear increase of $\mathrm{d}_{0^{-}}$and $\mathrm{d}_{1}$-BDE due to the reduction of thiophene conversion (see our Table 4, line 6) can be rather explained as the result of thiophene intermolecular hydrogen transfer. Such hydrogen redistribution in the initial thiophene HDS step (occurred likely during the primary catalytic interaction between thiophene molecules) is reasonable and comparable to that of dihydrothiophenes [21]; there is no other evident way to form any even minor amount of $\mathrm{d}_{0^{-}}$and $\mathrm{d}_{1}$-BDE molecules in the thiophene catalytic deuterodesulfurization. However, the detailed mechanism of such thiophene intermolecular hydrogen transfer in the HDS process is not simple to clarify. For instance, even 2,3- and 2,5-dihydrothiophenes show the significant disparity in D-patterns of 1,3-BDE molecules produced during the deuterodesulfurization (compare data in Tables 5, 6 in [21]). The largest excess of hydrogen 
atoms in 1,3-BDE produced from 2,5-DHT $\left(\mathrm{DN}_{\mathrm{BDE}}=\right.$ $0.51)$ in comparison with the amount of hydrogen atoms in 1,3-BDE produced from 2,3-DHT $\left(\mathrm{DN}_{\mathrm{BDE}}=4.06\right)$ distinctly points at a difference in the mechanistic details of this type of intermolecular hydrogen redistribution in [21]. Comparison of D-patterns of 2,3 and 2,5-DHTs clearly illustrates that even a different location of the only double bond could change "the picture" of hydrogen atoms redistribution during the catalytic interaction over the surface. In the case of thiophene HDS the intermolecular hydrogen transfer certainly has its own mechanism, which needs additional clarification as before by deuterium tracer experiments, but maybe at low conversions and other special conditions.

Acknowledgments During the preparation of this manuscript, A.B. had financial support by the European Union (Real-SOFC contract \# SES6-CT-2003-502612, and Marie Curie contract MIRG-CT-2006042095), and by the Swiss Competence Center for Energy and Mobility CCEM (project "Computational Engineering of Multi-Scale Transport in Small-Scale Surface Based Energy Conversion", CEMTEC).

\section{References}

1. Schuman SC, Shalit H (1971) Catal Rev 4:245

2. Amberg CH (1974) J Less Common Met 36:339

3. Zdrazil M (1982) Appl Catal 4:107

4. Vrinat ML (1983) Appl Catal 6:137
5. Prins R, De Beer VHJ, Samorjai GA (1989) Catal Rev 31:1

6. Topsøe H, Clausen BS, Massoth FE (1996) Hydrotreating catalysis. Science and technology. In: Anderson JR, Boudart M (eds) Catalysis-science and technology, vol 11. Springer-Verlag, Berlin

7. Kraus J, Zdrazil M (1977) React Kinet Catal Lett 6:475

8. Kieran P, Kemball C (1965) J Catal 4:394

9. Sullivan L, Ekerdt JG (1998) J Catal 178:226

10. Devanneaux J, Maurin J (1981) J Catal 69:202

11. Kolboe S (1969) Can J Chem 47:352

12. Satterfield CN, Roberts GW (1968) J Am Inst Chem Eng 14:159

13. Borgna A, Hensen EJM, Coulier L, de Croon MHJM, Schouten JC, van Veen JAR, Niemantsverdriet JW (2003) Catal Lett 90:117

14. Massoth FE (1977) J Catal 47:316

15. Lee HC, Butt JB (1977) J Catal 49:320

16. Gellman AJ, Neiman D, Somorjai GA (1987) J Catal 107:92

17. Gellman AJ, Bussell ME, Somorjai GA (1987) J Catal 107:103

18. Hensen EJM, Vissenberg MJ, de Beer VHJ, van Veen JAR, van Santen RA (1996) J Catal 163:429

19. Smith GV, Hincley CC, Behbahany F (1973) J Catal 30:218

20. Cowley SW (1975) Ph.D. Dissertation. Southern Illinois University, Carbondate, Illinois

21. Markel EJ, Schrader GL, Sauer NN, Angelici RJ (1989) J Catal 116:11

22. Mikovsky RI, Silvestri AI, Heineman H (1974) J Catal 34:324

23. Katsapov GYa, Khalikov RKh, Talipov GSh, Gudkov BS, Nekrasov NV (1978) Neftekhimiya 18:426

24. Katsapov GYa, Serodzhev AT (1986) React Kinet Catal Lett $31: 221$

25. McCarty KF, Schrader GL (1987) J Catal 103:261

26. Benson JW, Schrader GL, Angelici RJ (1995) J Mol Catal 96:283

27. Turkevich J, Taylor HS (1934) J Am Chem Soc 56:2254

28. Horiuty J, Polanyi M (1934) Trans Faraday Soc 30:1164

29. Kemball C (1972) Catal Rev 5:33 